ARTICLE

\title{
The COVID-19 pandemic impacts all domains of quality of life in Egyptians with spinal cord injury: a retrospective longitudinal study
}

\author{
Abdelrahman Elaraby ${ }^{1}$, Mostafa Shahein ${ }^{1}$, Amira Hassan Bekhet ${ }^{1}$, Paul B. Perrin (iD) ${ }^{2,3,4}$ and Ashraf S. Gorgey (iD) $3,4 \bowtie$ \\ This is a U.S. government work and not under copyright protection in the U.S.; foreign copyright protection may apply 2022
}

BACKGROUND AND OBJECTIVE: During the COVID-19 pandemic, several aspects of life have been affected. These aspects have been impacted especially in persons with spinal cord injury (SCI). The current study explored the overall effect of the COVID-19 pandemic on quality of life (QOL) domains in persons with $\mathrm{SCl}$ as well as evaluated their adherence to WHO-COVID 19-preventive measures.

DESIGN: A retrospective longitudinal study was conducted after asking participants to complete an online validated Arabic version of the WHOQOL-BREF questionnaires including their demographics. The WHOQOL-BREF questionnaires were completed targeting two separate occasions to represent their scores prior to and during the pandemic. Participants were asked to rate their adherence to WHO-COVID-19 preventive measures on a 10-point scale.

SETTING AND PARTICIPANTS: 115 participants with complete/ incomplete SCI were recruited via social media and contacted by phone to complete the questionnaires.

RESULTS: Persons with SCI had lower QOL scores during the COVID-19 period compared to their QOL during the pre-COVID-19 period; all QOL domains (Physical Health, Psychological, Social Relationships, and Environment) showed a significant decrease $(P<$ 0.001). Regarding COVID-19 preventative measures, participants were most likely to endorse self-isolation as well as staying home measures and least likely to adhere to hand washing and social distancing measures.

CONCLUSION: The robustly reduced QOL reported by individuals with SCI during the COVID-19 pandemic highlights the need for rehabilitation and mental health services, particularly administered via telehealth, to buffer the effects of the pandemic. Additionally, psychoeducation and support regarding COVID-19 preventative behaviors in this region would be critical.

Spinal Cord (2022) 60:757-762; https://doi.org/10.1038/s41393-022-00775-0

\section{INTRODUCTION}

COVID-19 or SARS-CoV-2 is a single-stranded RNA virus affecting the respiratory system in humans [1]. The outbreak of COVID-19 started in China in December, 2019 before spreading to other countries around the globe, affecting hundreds of millions of people and overwhelming health care systems [1, 2]. The impacts have extended to include multiple aspects of life including social, economic, health, and well-being. This has led officials and governments to declare a state of emergency and to require major social isolation measures that extended for more than 3-4 months in different countries across the globe. People were asked to maintain social isolation, wear face masks, and quarantine at home. In mid-March 2020, the World Health Organization (WHO) designated COVID-19 as a pandemic and declared a worldwide public health emergency [3].

In Egypt, health authorities identified the first case on February 14th, 2020 [4]. In March, 2020, the number of cases soared, prompting Egyptian authorities to declare a country-wide quarantine and impose a set of strict preventive regulations including home confinement, general lockdown, flight suspension, teleworking, prohibition of gatherings, and night-long curfew to contain the virus as much as possible [4]. Quarantine is one of the oldest and most effective preventive measures in containing previous outbreaks [5]. However, it is not a favorable choice due to limited freedom, long periods of loneliness, and family separation, which have detrimental repercussions on the psychological status, mental health, and quality of life (QOL) of the general population [6].

QOL can be defined as "the degree of need and satisfaction within the physical, psychological, social, activity, material, and structural area" of one's life [7]. QOL reflects the degree of satisfaction that an individual has towards his/her physical, psychological, and social aspects and the range of problems they may face within these domains. During the initial period of COVID19 , a Chinese study reported moderate-to-high levels of anxiety, apprehension, and fear associated with low levels of QOL [8]. In the Kingdom of Saudi Arabia, Algahtani et al. concluded that the COVID-19 pandemic and lockdown measures had significant

\footnotetext{
${ }^{1}$ Faculty of Physical Therapy, Cairo University, Giza, Egypt. ${ }^{2}$ Department of Psychology, Virginia Commonwealth University, Richmond, VA, USA. ${ }^{3}$ Department of Physical Medicine \& Rehabilitation, Virginia Commonwealth University, Richmond, VA, USA. ${ }^{4}$ Spinal Cord Injury and Disorders Center, Hunter Holmes McGuire VAMC, 1201 Broad Rock Boulevard, Richmond, VA 23249, USA. ${ }^{凶}$ email: ashraf.gorgey@va.gov
}

Received: 16 September 2021 Revised: 4 February 2022 Accepted: 8 February 2022

Published online: 26 February 2022 
effects on QOL especially for those who experienced depression, anxiety, and chronic diseases [9]. Several studies demonstrated that persons with chronic disorders similar to Parkinson's and spinal cord injury $(\mathrm{SCl})$ are at a risk for lower QOL $[10,11]$.

$\mathrm{SCl}$ can cause various complications and comorbidities that reduce QOL [12]. França et al. [13] and others [14] found that persons with $\mathrm{SCl}$ experience lower $\mathrm{QOL}$ than healthy controls. Conversely, more time for physical activity and sticking to homebased exercises $[15,16]$ may improve QOL among persons with $\mathrm{SCl}$. However, during the COVID-19 pandemic and respective quarantine, persons with $\mathrm{SCl}$ may have been at a higher risk of reduced QOL than before COVID-19. This might be attributed to the shift in rehabilitation resources and care toward COVID-19 patients without considering the basic needs for persons with $\mathrm{SCl}$. This may have resulted in reduction in hospital admissions for persons with $\mathrm{SCl}$ due to the fear of being infected with COVID-19, social distancing, and long curfew hours which confined persons with $\mathrm{SCl}$ within their homes, reducing their physical activity levels and increasing their unemployment rates [11].

Currently, there is not enough research addressing the impact of COVID-19 on QOL after SCl especially in Egypt. As a result, the current study aimed to assess the effect of the COVID-19 pandemic on $\mathrm{QOL}$ of individuals with $\mathrm{SCl}$ in Egypt. We hypothesized that the $\mathrm{QOL}$ of individuals with $\mathrm{SCl}$ would be substantially lower during the COVID-19 pandemic than before. We also hypothesized that individuals with $\mathrm{SCl}$ in the region would engage in a high level of COVID-19 preventative behaviors due in part to mandatory quarantine in the region, as well as the heightened risk for COVID19 complications among individuals with SCl.

\section{METHODS}

\section{Study design and participants}

We conducted a retrospective longitudinal study in Egypt between November 2020 and April 2021 among persons with SCl. Only Egyptian adults (aged $\geq 18$ years) diagnosed with traumatic SCl and permanently using a wheelchair were included in the trial. Participants were contacted twice via phone interview to complete questionnaires. Participants were required to be living in Egypt during the pre-COVID-19 and COVID-19 durations. The pre-COVID-19 and COVID-19 periods were retrospectively determined as the duration from July 2019 until December 2019, and from November 2020 and April 2021, respectively.

At the time of data collection, participants were not recruited from outpatient clinics or hospitals due to the total lockdown and quarantine status imposed by the government. So, participants were recruited based on convenience and snowball sampling techniques. Participants were invited to participate via social media groups. Different advertisements were posted announcing the need for participants with $\mathrm{SCl}$ and stating clearly the objectives and the eligibility criteria. Study staff then contacted respondents and scheduled phone interviews to provide more details and to ensure eligibility. Participants were then asked to read and sign an approved Arabic version of the consent form that clearly stated the primary objective of the study. This was then followed by providing medical documentation highlighting their identity, level of injury, and time since injury to be included in the data analysis.

Afterward, two study staff members contacted participants via phone interviews that ranged from $20-30 \mathrm{~min}$. Participants were then asked to answer each question of the questionnaire twice; the first for the preCOVID-19 period and the second for the COVID-19 and quarantine period. Researchers agreed to adopt similar strategies of introducing and explaining the questions to the participants to avoid any bias regarding the difference in understanding among participants. Participants were assured about the confidentiality of their data. The study was conducted in accordance with the Declaration of Helsinki. The study protocol and all measurements were approved by the Ethical Committee of the faculty of physical therapy, Cairo University (P.T.RECI012\002992).

\section{Study measures}

Data were collected on QOL and degree of adherence to WHO COVID-19 preventative behaviors. Additionally, participants were asked to complete a socio-demographic questionnaire including their age, months since injury, sex, educational level, marital status, and injury classification. Regarding the type of $\mathrm{SCl}$, the American Spinal Injury Association (ASIA) Impairment Scale (AIS) was used to categorize individuals with $\mathrm{SCl}$ into complete or incomplete SCl. AIS considers the lesion complete if there is no preservation of sensory and motor functions including the sacral roots below the level of the lesion. However, if the participant retains either sensory or motor functions below the level of the lesion, the injury is considered incomplete [17]. Owing to the quarantine restrictions, study staff were unable to collect data from participants in person and followed the gradients of the AIS impairment scale to assess the exact level of injury. Therefore, research staff asked participants about the preservation of the sense of internal anorectal wall during digital stimulation for bowel movements [18]. If the participant reported preserved sensation, the lesion was classified as incomplete. On the contrary, if the participant reported no perceived sensation, the lesion was classified as complete.

Quality of life (QOL). QOL was measured using the Arabic, validated version of WHOQOL-BREF questionnaire [19]. The scale consists of 26 items; the first two items address an individual's perception of his/her overall QOL and health, respectively, and the remaining 24 items assess the four QOL domains; Physical Health (seven items), Psychological (six items), Social Relationships (three items), and Environment (eight items). Each item is rated on a five-point Likert scale. The final scores were converted into a linear scale between 0 and 100 according to the scoring guidelines where higher scores indicate higher QOL.

WHO Covid-19 preventative behaviors. On a 10-point Likert scale, participants rated their adherence to the primary WHO behavioral measures for the public to avoid contracting COVID-19 [20].

\section{Data analysis}

All descriptive statistics and analyses were conducted using IBM SPSS Statistics 27. In order to determine whether there were differences in QOL domains and items as a function of the COVID-19 pandemic, a series of paired-samples $t$-tests was conducted. In each analysis, the independent variable was time (before vs. during the COVID-19 pandemic), and the independent variable was one of the four QOL domains (Physical Health, Psychological, Social Relationships, or Environment), the items comprising that domain, or one of the two items assessing general QOL or health satisfaction. Within each analysis, a Cohen's $d$ effect size was calculated taking into account the longitudinal correlation between each item or domain. An alpha level of 0.05 was used. Then, in order to identify the least and most common COVID-19 preventative behaviors among individuals with $\mathrm{SCl}$, means were calculated and graphed for each preventative behavior item.

\section{RESULTS}

Among the 115 participants with $\mathrm{SCl}, 95.7 \%$ were males while $4.3 \%$ were females. The mean age of participants was 29.89 years $(S D=6.70)$. The mean length of time since injury was 26.36 months $(S D=27.48)$. 93.9\% were diagnosed with paraplegia and $6.1 \%$ with tetraplegia. Detailed demographics and injury characteristics are shown in Table 1.

\section{Changes in QOL over Time}

The results of the paired-samples $t$-tests comparing QOL before vs. during the COVID-19 pandemic are presented in Table 2. All four overall QOL domains (Physical Health, Psychological, Social Relationships, and Environment) showed a statistically significant (all $p s<$ 0.001) decrease in individuals with $\mathrm{SCl}$ during the COVID-19 pandemic, generally approaching or exceeding medium-sized effects. Individuals with $\mathrm{SCl}$ also reported medium-sized decreases in their general QOL and health satisfaction. Within the Physical Health domain, the largest decreases occurred in participants' satisfaction in their ability to perform their daily living activities and in their energy for everyday life. Within the Psychological domain, the largest decreases occurred in participants' levels of enjoyment in life and how satisfied they were with themselves. In the Social Relationships domain, the largest decreases occurred in their satisfaction with their support from friends and in their personal relationships. In the Environment domain, the largest decreases 
Table 1. Characteristics of Individuals with SCI.

\begin{tabular}{lc}
\hline Demographic variable & Mean (SD) \\
\hline Age (years) & $29.89(6.70)$ \\
\hline Time since Injury (Months) & $26.36(27.48)$ \\
\hline Sex, $n$ (\%) & $110(95.7)$ \\
\hline Male & $5(4.3)$ \\
\hline Female & \\
\hline Education, $n$ (\%) & $9(7.8)$ \\
\hline Primary & $34(29.6)$ \\
\hline Secondary & $72(62.6)$ \\
\hline Tertiary & \\
\hline Marital status, $n(\%)$ & $48(41.7)$ \\
\hline Single/Divorced & $67(58.3)$ \\
\hline Married & \\
\hline AlS, $n$ (\%) & \\
\hline Complete & $89(77.4)$ \\
\hline Incomplete & $26(22.6)$ \\
\hline Classification, $n(\%)^{\mathrm{a}}$ & $108(93.9)$ \\
\hline Paraplegia & $7(6.1)$ \\
\hline Tetraplegia &
\end{tabular}

${ }^{a}$ AIS classification and classification of injury were self-reported during the phone interview.

occurred in the extent to which they had enough money to meet their needs and in their feelings of safety in their daily life.

\section{COVID-19 preventative behaviors}

Figure 1 presents the means of participants' responses regarding the COVID-19 preventative behaviour items. Participants were least likely to endorse appropriate hand washing behaviour and maintaining at least a 1-meter distance from other people. Conversely, participants were most likely to endorse staying at home and self-isolating when they had minor symptoms, as well as seeking medical attention immediately with COVID-19 symptoms.

\section{DISCUSSION}

The COVID-19 pandemic globally has created a major challenge to the health system due to the massive influx of COVID-19 patients into healthcare facilities and often needing long-term or intensive care. Consequently, health care facilities, especially neurological departments and neurosurgeons treating individuals with $\mathrm{SCl}$, have had to make major changes including forgoing many of the non-urgent elective surgeries and reducing patient volume [21]. Therefore, the World Health Organization (WHO) has established new specific recommendations with protective measures that should be taken by key stakeholders concerned with the care of people with disabilities including individuals with $\mathrm{SCl}$ [22].

Recommendations have included that telemedicine should be a mandatory tool to provide care to individuals with $\mathrm{SCl}$ during the COVID-19 pandemic. Telephone consultations, text messaging, and video conferencing could be used for the delivery of health care, psychosocial support, remote investigation, and follow up. The availability of telehealth services for individuals with $\mathrm{SCl}$ could lead to greater empowerment of individuals with $\mathrm{SCl}$ and their caregivers as well as better control of common problems. Consequently, this will reduce the need for urgent care and risks associated with hospital admission [23].

Therefore, following the $\mathrm{WHO}$ recommendations pertaining the use of the telecommunication strategies with individuals with disabilities, the current study used telephone calls to assess the effect of the COVID-19 pandemic and its respective preventive measures on QOL domains in Egyptian persons with $\mathrm{SCl}$.The results clearly indicated decreased $\mathrm{QOL}$ across all domains in persons with $\mathrm{SCl}$ during the COVID-19 pandemic. The findings are in line with previous work showing that persons with chronic illness are more likely to have lower QOL scores during the COVID19 and more vulnerable to COVID-19's negative effects on several other domains [24]. However, studies conducted on QOL of individuals with $\mathrm{SCl}$ before the COVID-19 pandemic also found lower scores in all domains than those for healthy individuals or people with other chronic disorders or diseases. Based on the literature $[25,26]$, it could be concluded that the results obtained in the current study showing lower $\mathrm{QOL}$ in individuals with $\mathrm{SCl}$ during the COVID-19 pandemic were to be expected.

This was reported in the domains of Physical Health (11.82 \pm 2.75), Psychological Health $(12.79 \pm 2.69)$, Social Relationships $(10.79 \pm 3.52)$, and Environment $(12.02 \pm 2.57)$, which is in line with the results from a study by Hearn et al [27]. Individuals with $\mathrm{SCl}$ during the COVID-19 pandemic experienced a variety of personal, physical, psychological, and social challenges, each of which could negatively affect daily functioning and QOL. The current results were in contrast to a study by Rudolf et al. [28] which reported no significant differences in individuals with $\mathrm{SCl}$ before and during the pandemic across any of the four WHOQOLBREF domains. However, when participants were stratified into two groups based on their age, the younger group (19-54 years) had lower scores during the COVID-19 pandemic in WHOQOLBREF Physical $(p=0.004)$ and Psychological domains $(p=0.007)$ than before, while the older group (55-88 years) reported no significant differences in any domain.

The Physical Health domain includes factors such as physical pain concerns, need for medical treatment to engage in daily functions, daily required energy, ability to get around, satisfaction with sleep, satisfaction with ability to perform daily living activities, and satisfaction with capacity for work [19]. The current results illuminated a significant decrease in scores on the physical health domain during the COVID-19 pandemic compared to the pre-pandemic period. These results contradict a Spanish study which concluded the absence of any significant differences between the COVID-19 and pre-pandemic periods regarding physical health [28]. However, according to the results, the largest decreases were reported in participants' satisfaction in the ability to perform daily living activities and reduction in energy for everyday life activities. Hearn et al. [27] suggested that the deterioration in physical health is due to difficulty in accessing health services, especially physical therapy rehabilitation centers, in addition to increased probability of infection that remains the most common reason for mortality following SCI [29]. Several studies from other countries including Tanzania [30], Canada [31], and Hong Kong [32] reported that persons with $\mathrm{SCl}$ had more negative impacts on the Physical Health domain compared to the Psychological, Social, and Environmental health domains. The current results were in accordance with several studies reporting that the COVID-19 pandemic has led to increasing sleep problems $[33,34]$. Sleep disturbance is associated with adverse effects on an individual's psychological, cognitive, and social functioning and leads to worsening of overall QOL [35].

The Psychological Health domain includes extent of enjoyment in life, feeling of life to be meaningful, ability to concentrate, acceptance of bodily appearance, self-satisfaction, and rating of negative feelings such as blue mood, despair, anxiety, and depression [19]. The current results showed a significant worsening of psychological health during the COVID-19 period compared to the pre-pandemic period. These results are in line with a Japanese study showing that $44.4 \%$ of participants experienced worsened anxiety and depression symptoms during the COVID-19 period compared to the pre-pandemic period [36]. On the contrary, García-Rudolph et al. reported no significant difference 
Table 2. Changes in quality of life before vs. during the COVID-19 pandemic.

\begin{tabular}{|c|c|c|c|c|c|c|}
\hline Quality of life question or domain & Mean before & SD before & Mean during & SD during & $p$ value & Cohen's $d$ \\
\hline How would you rate your quality of life? & 3.51 & 1.18 & 2.72 & 1.17 & 0.000 & 0.68 \\
\hline How satisfied are you with your health? & 3.67 & 1.20 & 2.93 & 1.31 & 0.000 & 0.60 \\
\hline Physical Health & 12.85 & 2.68 & 11.82 & 2.75 & 0.000 & 0.45 \\
\hline $\begin{array}{l}\text { To what extent do you feel that physical pain prevents you } \\
\text { from doing what you need to do? }\end{array}$ & 2.95 & 1.50 & 3.10 & 1.43 & 0.091 & -0.16 \\
\hline $\begin{array}{l}\text { How much do you need any medical treatment to function in } \\
\text { your daily life? }\end{array}$ & 3.10 & 1.42 & 3.20 & 1.37 & 0.346 & -0.09 \\
\hline Do you have enough energy for everyday life? & 3.56 & 1.24 & 3.03 & 1.39 & 0.000 & 0.39 \\
\hline How well are you able to get around? & 3.31 & 1.27 & 3.01 & 1.27 & 0.006 & 0.26 \\
\hline How satisfied are you with your sleep? & 3.32 & 1.20 & 2.99 & 1.26 & 0.000 & 0.33 \\
\hline $\begin{array}{l}\text { How satisfied are you with your ability to perform your daily } \\
\text { living activities? }\end{array}$ & 3.36 & 1.08 & 2.88 & 1.17 & 0.000 & 0.46 \\
\hline How satisfied are you with your capacity for work? & 2.88 & 1.51 & 2.48 & 1.42 & 0.001 & 0.32 \\
\hline Psychological & 13.96 & 2.94 & 12.79 & 2.69 & 0.000 & 0.45 \\
\hline How much do you enjoy life? & 3.49 & 1.31 & 2.92 & 1.22 & 0.000 & 0.43 \\
\hline To what extent do you feel your life to be meaningful? & 3.37 & 1.50 & 3.03 & 1.41 & 0.002 & 0.29 \\
\hline How well are you able to concentrate? & 4.02 & 1.04 & 3.63 & 1.20 & 0.000 & 0.39 \\
\hline Are you able to accept your bodily appearance? & 3.53 & 1.27 & 3.57 & 1.30 & 0.784 & -0.03 \\
\hline How satisfied are you with yourself? & 3.47 & 1.39 & 3.13 & 1.38 & 0.000 & 0.43 \\
\hline $\begin{array}{l}\text { How often do you have negative feelings such as blue mood, } \\
\text { despair, anxiety, depression? }\end{array}$ & 3.07 & 1.34 & 2.91 & 1.38 & 0.126 & 0.14 \\
\hline Social relationships & 11.99 & 3.02 & 10.79 & 3.52 & 0.000 & 0.48 \\
\hline How satisfied are you with your personal relationships? & 3.69 & 1.20 & 3.29 & 1.34 & 0.000 & 0.37 \\
\hline How satisfied are you with your sex life? & 1.45 & 1.02 & 1.41 & 0.97 & 0.227 & 0.11 \\
\hline $\begin{array}{l}\text { How satisfied are you with the support you get from your } \\
\text { friends? }\end{array}$ & 3.85 & 1.17 & 3.40 & 1.36 & 0.000 & 0.47 \\
\hline Environment & 13.18 & 2.64 & 12.02 & 2.57 & 0.000 & 0.62 \\
\hline How safe do you feel in your daily life? & 3.74 & 1.30 & 3.32 & 1.41 & 0.001 & 0.33 \\
\hline How healthy is your physical environment? & 2.92 & 1.38 & 2.71 & 1.30 & 0.014 & 0.23 \\
\hline Have you enough money to meet your needs? & 3.32 & 1.36 & 2.74 & 1.36 & 0.000 & 0.45 \\
\hline $\begin{array}{l}\text { How available to you is the information that you need in your } \\
\text { day-to-day life? }\end{array}$ & 4.02 & 1.16 & 3.79 & 1.38 & 0.019 & 0.22 \\
\hline $\begin{array}{l}\text { To what extent do you have the opportunity for leisure } \\
\text { activities? }\end{array}$ & 3.31 & 1.23 & 3.19 & 1.31 & 0.232 & 0.11 \\
\hline How satisfied are you with the conditions of your living place? & 3.23 & 1.41 & 2.94 & 1.49 & 0.002 & 0.29 \\
\hline How satisfied are you with your access to health services? & 2.74 & 1.53 & 2.39 & 1.47 & 0.001 & 0.31 \\
\hline How satisfied are you with your transport? & 3.07 & 1.47 & 2.95 & 1.51 & 0.068 & 0.17 \\
\hline
\end{tabular}

between the pre-pandemic and COVID-19 periods pertaining to psychological health [28]. Additionally, the largest decreases occurred in participants' levels of enjoyment in life and how satisfied they were with themselves. These results were accordance with Hearn et al. [27] who reported a substantial deterioration regarding the psychological aspects of life among individual with $\mathrm{SCl}$. This deterioration could be attributed to the lack of access to healthcare facilities and the obligatory isolation due to quarantine.

The Social Relationships domain includes factors such as satisfaction with personal relationships, sexual activity, and satisfaction with support from friends [19]. The current results showed a significant decrease regarding social QOL during the COVID-19 period in comparison to the pre-pandemic period. These results are not in line with those reported by García-Rudolph et al. who showed no difference between the prepandemic and COVID-19 periods regarding the social aspect of the WHOQOL-BREF [28]. The largest decreases were reported in satisfaction with support received from friends and their personal relationships. That may be due to the mandatory social distancing policies applied in this period to protect highly vulnerable individuals to infection by not leaving their homes and minimizing all face-to-face contact and staying at home. Being unable to use a wheelchair in the more prolonged ways they usually do would leads to some functional losses, isolation that induces frustration, depression, low mood, anxiety [37], and poorer QOL [38].

The Environmental domain includes factors such as the perception of freedom, physical security, financial security, social and health care, satisfaction with the conditions of one's living place, opportunities to gain new information and skills, activity participation, and opportunities for leisure activities. These factors have been influenced by restrictive measures in addition to curfew hours which confined individuals with $\mathrm{SCl}$ within their homes. Therefore, the results uncovered a significant decrease during the COVID-19 period compared to the pre-pandemic period, and this contradicts prior results reported by García-Rudolph et al. [28]. However, according to the current results, the largest decreases were reported in the extent to which participants had enough money to meet their needs and in their feelings of safety in their daily life. However, studies conducted before the COVID-19 pandemic also reported lower scores in the Environmental domain [39]. Therefore, although the pandemic may have influenced this domain, individuals with $\mathrm{SCl}$ already had low environmental QOL. 


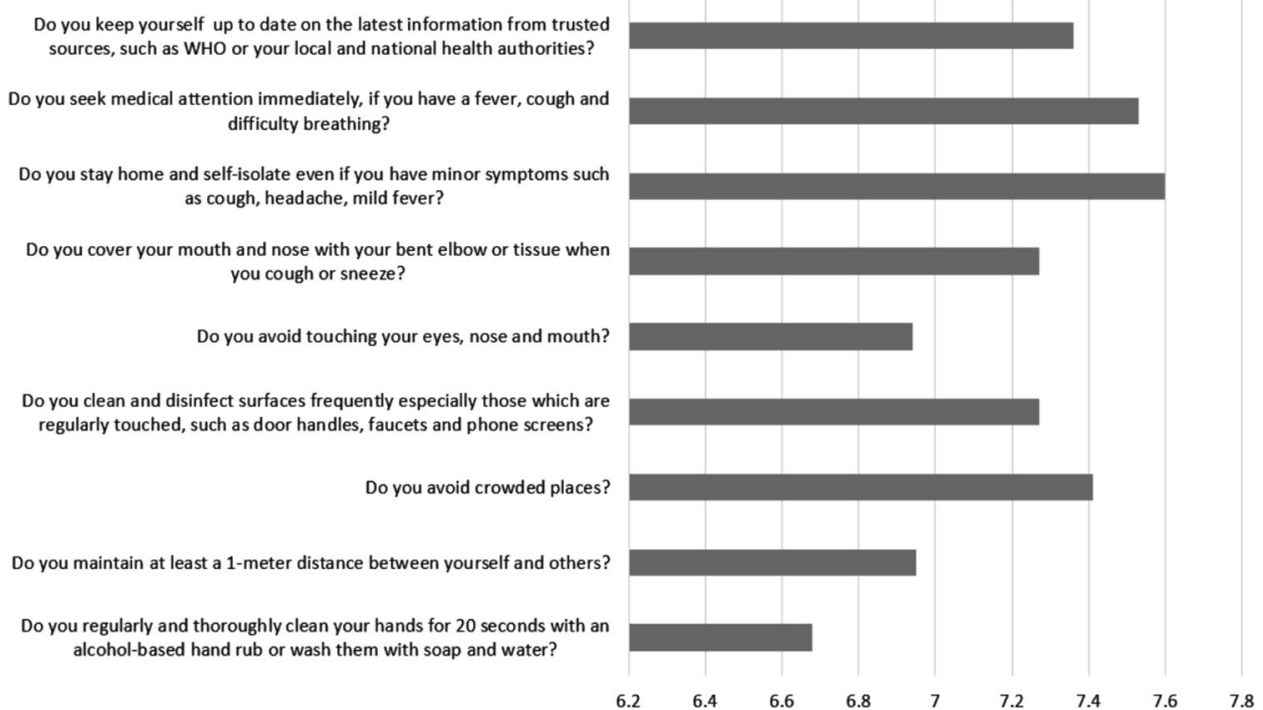

Fig. 1 Frequency of COVID-19 preventative behaviors (rated 1-10). The behavior measures were rated after administering the items in a random order to each participant and allow each participant enough time to think and provide his/her answer.

\section{COVID-19 preventative behaviors}

Regarding adherence of participants to COVID-19 preventive measures, this study showed that individuals with $\mathrm{SCl}$ were less likely engage in appropriate hand washing behavior likely due to mobility restriction and environmental barriers that not only hinder the individuals with $\mathrm{SCl}$ from optimal hygienic practice but also limit their ability to exercise and rehabilitate sufficiently [40, 41]. This finding was in line with a study conducted in developing countries finding that individuals with disabilities have poorer access to adequate water that is required for hygiene and sanitation within their households [42]. In contrast, Abd Elhameed Ali et al. found that the majority of Egyptian participants showed high adherence to hand washing behavior, coughing, and sneezing hygiene [43].

The current results showed that individuals with $\mathrm{SCl}$ were least likely to adhere to maintaining at least a 1-meter distance from other people. The results were in line with previous findings regarding the social distancing measures and may attributed to Egyptian customs and traditions [43, 44]. Egyptian persons with $\mathrm{SCl}$ may be most likely to self-isolate and seek medical attention once they contract mild symptoms in accordance with WHO preventive measures, and this could be attributed to good knowledge of COVID-19 symptoms among the Egyptian population [45].

\section{Limitations}

The study design was an observational retrospective longitudinal study which hinders the possibility to infer a causal relationship. In addition, due to the quarantine and lockdown measures, individuals with $\mathrm{SCl}$ have been less inclined to attend their appointments in outpatient clinics, underscoring the importance of establishing a remote study approaches and follow up of these patients. In the current study, the investigators proactively contacted individuals with $\mathrm{SCl}$ by telephone. The study only recruited and contacted individuals with $\mathrm{SCl}$ who use social media, limiting the ability to reach other individuals who do not use social media. This may explain why the participants were recently injured. Recently injured individuals may represent most of the individuals who are still looking for cures and have access to social media compared to older Egyptian adults with SCI. Two investigators were responsible for contacting participants and gathering data which may have introduced a minor degree of performance bias due to the difference in the way of conveying the questions to participants, although, this was likely overcome by adopting similar strategies as far as introducing and explaining the questions to the participants. The questionnaire included questions about the participants' QOL during the pre-COVID 19 periods, so participants answered the questions depending solely on their memories which may have introduced recall bias. Participants had attained different levels of education, and this may have affected their levels of understanding of the questionnaire, providing another opportunity for response bias. No information was collected about participants' vaccination or COVID-19 diagnosis history, and as a result future research would benefit from tying these variables to COVID-19 preventative behaviors and QOL. Lastly, the small and unrepresentative sample and the convenience sampling method hinder the generalizability of the results, and as a result, readers must interpret the results with an appropriate degree of caution.

\section{CONCLUSION}

The study concluded that Egyptian persons with $\mathrm{SCl}$ had lower levels of the four domains of QOL (Physical Health, Psychological, Social Relationships, and Environment) during the COVID-19 pandemic when compared to their QOL during the pre-COVID19 period. Regarding the COVID-19 preventive measures, Egyptian persons with $\mathrm{SCl}$ may be more likely to adhere to self-isolation and seeking medical attention once they contract mild symptoms. However, they showed low adherence to hand washing and social distancing measures. The robustly reduced $\mathrm{QOL}$ reported by individuals with $\mathrm{SCl}$ in Egypt during the COVID-19 pandemic highlights the need for rehabilitation and mental health services, particularly administered via telehealth, to buffer the effects of the pandemic. Additionally, psychoeducation and support regarding COVID-19 preventative behaviors in this region would be critical.

\section{DATA AVAILABILITY}

The data was uploaded as supplementary material for review process only. After acceptance of the paper, the data will be available upon email communications with the corresponding author.

\section{REFERENCES}

1. Liu Y-C, Kuo R-L, Shih S-R. COVID-19: the first documented coronavirus pandemic in history. Biomed J 2020;43:328-33.

2. COVID-19 Map [Internet]. Johns Hopkins Coronavirus Resource Center. 2020 [cited 2021 Aug 13]. Available from: https://coronavirus.jhu.edu/map.html 
3. Mahase E. China coronavirus: WHO declares international emergency as death toll exceeds 200. BMJ 2020;368:m408.

4. Medhat MA, El Kassas M. COVID-19 in Egypt: uncovered figures or a different situation? J Glob Health. 2020;10:010368.

5. Conti AA Quarantine Through History. International Encyclopedia of Public Health. 2008:454-62.

6. Brooks SK, Webster RK, Smith LE, Woodland L, Wessely S, Greenberg N, et al. The psychological impact of quarantine and how to reduce it: rapid review of the evidence. Lancet. 2020;395:912-20.

7. Post M. Definitions of quality of life: what has happened and how to move on. Top Spinal Cord Inj Rehabilitation 2014;20:167-80.

8. Zhang Y, Ma ZF. Impact of the COVID-19 pandemic on mental health and quality of life among local residents in Liaoning Province. China: A Cross-Sect Study IJERPH. 2020;17:2381.

9. Algahtani FD, Hassan S-N, Alsaif B, Zrieq R. Assessment of the quality of life during COVID-19 pandemic: a cross-sectional survey from the kingdom of Saudi Arabia. IJERPH. 2021;18:847.

10. Guo D, Han B, Lu Y, Lv C, Fang X, Zhang Z, et al. Influence of the COVID-19 pandemic on quality of life of patients with Parkinson's Disease. Teive $\mathrm{H}$, editor. Parkinson's Disease. 2020;2020:1216568.

11. Felix E, Alvarado JV, Miranda-Cantellops N, Jackson S. Access limitations and level of psychological distress during the Covid-19 pandemic in a sample of individuals with spinal cord injury. Arch Phys Med Rehabilitation. 2021;102:e5-6.

12. Tulsky DS, Kisala PA, Victorson D, Tate DG, Heinemann AW, Charlifue S, et al. Overview of the spinal cord injury - quality of life (SCI-QOL) measurement system. J Spinal Cord Med. 2015;38:257-69.

13. França ISX, de, Coura AS, França EG, de, Basílio NNV, Souto RQ. Qualidade de vida de adultos com lesão medular: um estudo com WHOQOL-bref. Rev esc enferm USP. 2011;45:1364-71

14. Trgovcevic S, Milicevic M, Nedovic G, Jovanic G. Health condition and quality of life in persons with spinal cord injury. Iran J Public Health. 2014;43:1229-38.

15. Mickens MN, Perrin P, Goldsmith JA, Khalil RE, Carter lii WE, Gorgey AS. Leisuretime physical activity, anthropometrics, and body composition as predictors of quality of life domains after spinal cord injury: an exploratory cross-sectional study. Neural Regen Res. 2022;17:1369-75.

16. Dolbow DR, Gorgey AS, Ketchum JM, Gater DR. Home-based functional electrical stimulation cycling enhances quality of life in individuals with spinal cord injury. Top Spinal Cord Inj Rehabil. 2013;19:324-9.

17. Roberts TT, Leonard GR, Cepela DJ. Classifications In Brief: American Spinal Injury Association (ASIA) Impairment Scale. Clin Orthop Relat Res. 2017;475:1499-504.

18. Kirshblum SC, Burns SP, Biering-Sorensen F, Donovan W, Graves DE, Jha A, et al International standards for neurological classification of spinal cord injury (Revised 2011). J Spinal Cord Med. 2011;34:535-46.

19. Ohaeri JU, Awadalla AW. The reliability and validity of the short version of the WHO Quality of Life Instrument in an Arab general population. Ann Saudi Med. 2009;29:98-104.

20. Advice for the public [Internet]World Health Organization. 2019 [cited 2021 Aug 13]. Available from: https://www.who.int/emergencies/diseases/novelcoronavirus-2019/advice-for-public

21. Jean WC, Ironside NT, Sack KD, Felbaum DR, Syed HR. The impact of COVID-19 on neurosurgeons and the strategy for triaging non-emergent operations: a global neurosurgery study. Acta Neurochir (Wien). 2020;162:1229-40.

22. Disability considerations during the COVID-19 outbreak [Internet]World Health Organization. 2020 [cited 2021 Dec 5]. Available from: https://www.who.int/ publications-detail-redirect/WHO-2019-nCoV-Disability-2020-1

23. Sánchez-Raya J, Sampol J. Spinal cord injury and COVID-19: some thoughts after the first wave. Spinal Cord. 2020:58:841-3.

24. Ping W, Zheng J, Niu X, Guo C, Zhang J, Yang H, et al. Evaluation of health-related quality of life using EQ-5D in China during the COVID-19 pandemic. PLoS One. 2020;15:e0234850.

25. Hu Y, Mak J, Wong Y, Leong J, Luk K. Quality of life of traumatic spinal cord injured patients in Hong Kong. Acta Derm Venereol. 2008;40:126-31.

26. Rofi'i AYAB, Maria R, Masfuri. Quality of life after spinal cord injury: an overview. Enfermería Clínica. 2019:29:1-4.

27. Hearn JH, Rohn EJ, Monden KR. Isolated and anxious: a qualitative exploration of the impact of the COVID-19 pandemic on individuals living with spinal cord injury in the UK. J Spinal Cord Med. 2021;0:1-9.

28. García-Rudolph A, Saurí J, López Carballo J, Cegarra B, Wright MA, Opisso E, et al. The impact of COVID-19 on community integration, quality of life, depression and anxiety in people with chronic spinal cord injury. J Spinal Cord Med. 2021;1-10.

29. van den Berg MEL, Castellote JM, de Pedro-Cuesta J, Mahillo-Fernandez I. Survival after spinal cord injury: a systematic review. J Neurotrauma. 2010;27:1517-28.
30. Moshi H, Sundelin G, Sahlen K-G, Sörlin A. Quality of life of persons with traumatic spinal cord injury in rural Kilimanjaro, Tanzania: a community survey. Disability and Rehabilitation. 2021;43:2838-45.

31. Leduc BE, Lepage Y. Health-related quality of life after spinal cord injury. Disabil Rehabilitation. 2002;24:196-202.

32. Hu Y, Mak J, Wong Y, Leong J, Luk K. Quality of life of traumatic spinal cord injured patients in Hong Kong. J Rehabilitation Med. 2008;40:126-31.

33. Grossman ES, Hoffman YSG, Palgi Y, Shrira A. COVID-19 related loneliness and sleep problems in older adults: Worries and resilience as potential moderators. Personal Individ Differences. 2021;168:110371.

34. Altena E, Baglioni C, Espie CA, Ellis J, Gavriloff D, Holzinger B, et al. Dealing with sleep problems during home confinement due to the COVID-19 outbreak: Practical recommendations from a task force of the European CBT-I Academy. J Sleep Res. 2020;29:e13052.

35. Szentkirályi A, Madarász CZ, Novák M. Sleep disorders: impact on daytime functioning and quality of life. Expert Rev Pharmacoeconomics Outcomes Res. 2009:9:49-64.

36. Matsuoka M, Sumida M. The effect of the COVID-19 pandemic on the healthrelated quality of life in home-based patients with spinal cord injuries in Japan. The J of Spinal Cord Med. 2021;1-5.

37. Abad C, Fearday A, Safdar N. Adverse effects of isolation in hospitalised patients: a systematic review. J Hospital Infect. 2010;76:97-102.

38. Sharma A, Pillai DR, Lu M, Doolan C, Leal J, Kim J, et al. Impact of isolation precautions on quality of life: a meta-analysis. J Hospital Infect. 2020;105:35-42.

39. Chang F, Xie H, Zhang Q, Sun M, Yang Y, Chen G, et al. Quality of life of adults with chronic spinal cord injury in mainland china: a cross-sectional study. J Rehabil Med. 2020;52:jrm00058.

40. Swarnakar R, Santra S. Personal hygiene care in persons with spinal cord injury during the COVID-19 pandemic and lockdown: an Indian perspective. Spinal Cord Ser Cases. 2020;6:76.

41. Gorgey AS. Exercise awareness and barriers after spinal cord injury. World J Orthop. 2014;5:158-62.

42. Mactaggart I, Schmidt W-P, Bostoen K, Chunga J, Danquah L, Halder AK, et al. Access to water and sanitation among people with disabilities: results from crosssectional surveys in Bangladesh, Cameroon, India and Malawi. BMJ Open. 2018;8: e020077.

43. Abd Elhameed Ali R, Ahmed Ghaleb A, Abokresha SA. COVID-19 related knowledge and practice and barriers that hinder adherence to preventive measures among the Egyptian community. An epidemiological study in Upper Egypt. J Public Health Res. 2021;10.

44. Bakry HM. Perception and practice of social distancing among Egyptians in COVID-19 pandemic. J Infect Dev Ctries. 2020;14:817-22.

45. Kasemy ZA, Bahbah WA, Zewain SK, Haggag MG, Alkalash SH, Zahran E, et al. Knowledge, Attitude and Practice toward COVID-19 among Egyptians: JEGH. 2020;10:378.

\section{AUTHOR CONTRIBUTIONS}

Conceptualization: ASG, AHB, MS, PBP, and AE; Data acquistion: MS and AE; Analysis and interpretation of data: PBP; Drafting of the manuscript: ASG, AHB, MS, PBP, and $A E ;$ Critical revision of the manuscript: ASG and PBP; Study supervision: ASG.

\section{COMPETING INTERESTS}

The authors declare no competing interests.

\section{ETHICAL APPROVAL}

We certify that all applicable institutional and governmental regulations concerning the ethical use of human volunteers were followed during the course of this research.

\section{ADDITIONAL INFORMATION}

Correspondence and requests for materials should be addressed to Ashraf S. Gorgey.

Reprints and permission information is available at http://www.nature.com/reprints

Publisher's note Springer Nature remains neutral with regard to jurisdictional claims in published maps and institutional affiliations. 